\title{
Produtividade e valor nutricional de variedades de cana-de-açúcar sob diferentes fontes de fósforo
}

\section{Productivity and nutritional value varieties of sugarcane under different phosphorus sources}

\author{
Gustavo Caione ${ }^{1 *}$; Francisco Maximino Fernandes ${ }^{2}$; Anderson Lange ${ }^{3}$; Antonio \\ Fernando Bergamaschine ${ }^{4}$; Flávio Carlos Dalchiavon ${ }^{5}$; Amilton Ferreira da Silva ${ }^{6}$
}

\section{Resumo}

Com a expansão da cana-de-açúcar em áreas nas quais não é tradicional seu cultivo, há a necessidade de se estudar o manejo da adubação, principalmente do fósforo, que é o nutriente que mais limita a produção em regiões de clima tropical. O objetivo deste trabalho foi avaliar a produtividade e o valor nutricional de duas variedades de cana-de-açúcar cultivada com diferentes fontes de fósforo, durante três ciclos de produção no Norte do Mato Grosso. O delineamento experimental utilizado foi o de blocos ao acaso, em esquema fatorial $4 \times 2$, com quatro repetições. As fontes de fósforo utilizadas foram a farinha de ossos, fosfato de Arad e superfosfato triplo, na dose de $100 \mathrm{~kg} \mathrm{ha}^{-1} \mathrm{de}_{2} \mathrm{P}_{5}$ e, um controle, sem aplicação do nutriente no sulco de plantio. As variedades de cana-de-açúcar plantadas foram a IAC86-2480 e a SP79-1011. Avaliou-se a produtividade de matéria seca, teor de matéria seca, fibra em detergente neutro e, em detergente ácido, lignina, celulose, digestibilidade in vitro e proteína bruta da forragem. As fontes de fósforo proporcionaram maiores produtividades durante o primeiro ciclo da cana-de-açúcar e não causaram efeito significativo na produtividade nos ciclos posteriores. A adubação fosfatada não promoveu alterações significativas no valor nutricional da cana-de-açúcar. A variedade IAC86-2480 apresentou maior teor de proteína bruta nos três ciclos e maior produtividade de matéria seca nos dois primeiros ciclos, em relação a SP79-1011. Em relação aos constituintes fibrosos, ambas as variedades apresentaram resultados semelhantes.

Palavras-chave: Saccharum spp., forragem, adubação fosfatada, composição bromatológica, farinha de ossos

\footnotetext{
Abstract

Due to the expansion of sugarcane in areas that are not traditional in it's cultivation, there is need of study the management of fertilizer, mainly phosphorus, since it's the nutrient that most limits the production in the tropics. The aim of this work was to evaluate the productivity and nutritional value of two varieties of sugarcane grown under different phosphorus sources, for three production cycles in North of Mato Grosso State, Brazil. The experimental design was randomized blocks in factorial scheme

${ }^{1}$ Doutorando em Agronomia, Universidade Estadual Paulista “Júlio de Mesquita Filho”, FCAV/UNESP, Jaboticabal, SP. E-mail: gustavocaione@agronomo.eng.br

${ }^{2}$ Prof. Dr. do Dept ${ }^{\circ}$ de Fitossanidade, Engenharia Rural e Solos, FEIS/UNESP, Ilha Solteira, SP. E-mail: maximino@agr.feis.unesp.br

${ }^{3}$ Prof. Dr. do Instituto de Ciências Agrárias e Ambientais, Universidade Federal de Mato Grosso, UFMT de Sinop, MT. E-mail: paranalange@hotmail.com

${ }^{4}$ Prof. Dr. do Dept ${ }^{\circ}$ de Biologia e Zootecnia, FEIS/UNESP de Ilha Solteira, SP. E-mail: berga@bio.feis.unesp.br

${ }^{5}$ Prof. Dr. do Dept ${ }^{\circ}$ de Agronomia, Instituto Federal de Educação, Ciência e Tecnologia de Mato Grosso, Campus Campo Novo do Parecis, Mato Grosso, MT. E-mail: flavio.dalchiavon@cnp.ifmt.edu.br

${ }^{6}$ Doutorando em Agronomia, Universidade Federal de Viçosa, UFV, MG. E-mail: amilton@agronomo.eng.br

* Autor para correspondência
} 
$4 \times 2$, with four replications. The sources of phosphorus used were bone meal, Arad phosphate and triple superphosphate at a dose of $100 \mathrm{~kg} \mathrm{P}_{2} \mathrm{O}_{5} \mathrm{ha}^{-1}$, and a control without nutrient application at planting. The varieties of sugarcane were planted IAC86-2480 and SP79-1011. We evaluated the productivity of dry matter, dry matter content, neutral detergent fiber and acid detergent, lignin, cellulose, in vitro digestibility and crude protein of forage. The phosphorus sources provided higher yields during the first cycle of sugarcane and did not cause significant effect on productivity in subsequent cycles. Phosphorus fertilization did not cause significant changes in the nutritional value of sugarcane. The variety IAC862480 showed higher crude protein content in three cycles and higher dry matter yield in the first two cycles, compared to SP79-1011. Regarding the fiber constituents, both showed similar results.

Key words: Saccharum spp., forage, phosphate fertilization, chemical composition, bone meal

\section{Introdução}

No Norte do estado de Mato Grosso, a exploração pecuária é baseada no fornecimento de alimentos aos bovinos através das pastagens, sendo a maneira mais prática e econômica. No entanto, essas pastagens se encontram com vários anos de exploração, sem receber nenhuma adubação e, assim, a estação seca torna-se ainda mais agravante, necessitando de um período de descanso das pastagens. Neste contexto, há uma crescente demanda pelo plantio da canade-açúcar, que se apresenta como uma alternativa, devido seu período de corte coincidir com a estação seca, produtividade elevada de forragem, fácil cultivo, manutenção do seu valor nutricional durante longo tempo, além de permitir vários cortes (FERNANDES et al., 2001).

O comportamento da cana-de-açúcar é diferente de outras gramíneas tropicais, pois, com o avanço da idade ocorre uma melhoria na qualidade nutricional da forragem. De acordo com Resende et al. (2003), quando em estádio final de maturação, o teor de fibra em detergente neutro da cana-de-açúcar é baixo, comparado a outras forrageiras tropicais. No entanto, apresenta características que limitam a sua utilização por animais de elevado potencial genético, dentre as quais se destacam o baixo teor de proteína bruta, fibra de lenta degradação ruminal e elevado teor de fibra não-degradável, que limita a ingestão de matéria seca (PEREIRA et al., 2001), havendo a necessidade de seleção de variedades com maiores teores de proteína bruta, adequada digestibilidade, aliada a altas produtividades. Por isso, a escolha da cultivar é uma das decisões de manejo mais importantes, sendo que essa escolha frequentemente significa a diferença entre lucro e prejuízo (SALAZAR et al., 2010).

O valor nutritivo de uma planta forrageira não deve ser considerado como fator isolado, mas como um complexo formado por composição química, digestibilidade e constituintes secundários que, em conjunto, podem interferir na ingestão e utilização da forragem consumida pelos ruminantes. Numa variedade forrageira, o valor nutritivo varia de acordo com idade e parte da planta, fertilidade do solo, adubação recebida, entre outros (Van SOEST, 1994). Sendo assim, o manejo adequado da adubação é de crucial importância, sobretudo do fósforo (P), que em solos de clima tropical, a fração mineralógica é composta principalmente por argilas tipo caulinita e óxi-hidróxidos de Fe e de Al (NOVAIS; SMYTH, 1999) e, assim, o P é o nutriente que mais limita o desenvolvimento e produtividade das culturas (SANTOS et al., 2002). No entanto, são raros os trabalhos que relacionam o efeito da adubação com o valor nutricional da canade-açúcar.

As principais fontes de adubos fosfatados são classificadas, basicamente, em solúveis, pouco solúveis e insolúveis. As fontes solúveis são prontamente disponíveis e, por isso, são mais utilizadas. Esta rápida liberação pode, também, favorecer o processo de adsorção e precipitação das formas solúveis aos componentes do solo (HOROWITZ; MEURER, 2003), uma vez que a absorção ocorre de forma lenta e, assim, grande parte do P lábil que não for absorvido pela planta 
passará para a forma não lábil, pois, com o passar do tempo, formas mais estáveis de $\mathrm{P}$ são formadas.

A utilização da farinha de ossos como fonte alternativa de $\mathrm{P}$ tem despertado interesse na região norte do estado de Mato Grosso, principalmente em função do baixo custo por unidade de $\mathrm{P}$, em relação às demais fontes. Atualmente as indústrias frigoríficas localizadas no município de Alta Floresta, abatem diariamente 1.000 bovinos, em média, gerando uma quantidade significativa de farinha de ossos. Contudo, a demanda pelo produto é baixa e, assim, tem-se disponível um produto orgânico que pode apresentar boa eficiência para fins de adubação, já que apresenta teores significativos de $\mathrm{P}$ e Ca, além de outros elementos em menores concentrações (Na, Fe, Zn, S e Si) (AVELAR et al., 2009).

Visto a elevada capacidade de adsorção de P que os solos da região norte mato-grossense apresentam, aliado aos baixos teores naturais, torna necessário o estudo de fontes alternativas do nutriente e, as possíveis alterações causadas no valor nutritivo da forragem, além da tentativa de reduzir custos referentes à adubação fosfatada. Busca-se, também, a identificação de variedades de cana-de-açúcar que melhor se adaptam a esta região, que é caracterizada pela produção animal a pasto, onde a cana-de- açúcar é a principal forrageira utilizada na estação seca do ano, especialmente por pequenos e médios produtores.

Este trabalho teve por objetivo avaliar a produtividade e o valor nutricional de duas variedades de cana-de-açúcar, durante três ciclos, sob efeito da aplicação de diferentes fontes de fósforo no sulco de plantio na região Norte do Mato Grosso.

\section{Material e Métodos}

$\mathrm{O}$ experimento foi realizado no município de Alta Floresta - MT, (959'03"'S e 56 $\left.07^{\circ} 47^{\prime \prime} \mathrm{W}\right)$, com altitude média de $300 \mathrm{~m}$. O clima predominante é do tipo AWI - classificação Köppen, clima tropical chuvoso com nítida estação seca e com temperaturas entre $20^{\circ}$ a $38^{\circ} \mathrm{C}$, tendo em média $26^{\circ} \mathrm{C}$. A pluviosidade média anual dos últimos 10 anos foi de $2.550 \mathrm{~mm}$ e os dados de precipitação pluvial coletados durante o período de condução do experimento (novembro de 2007 a julho de 2010) encontram-se na Figura 1. Observa-se que a pluviosidade total registrada na cana planta foi de $2.153 \mathrm{~mm}$, na primeira soca $2.520 \mathrm{~mm}$ e na segunda soca $2.244 \mathrm{~mm}$.

Figura 1. Precipitação pluvial durante o período de condução do experimento. Alta Floresta - MT (novembro de 2007 a julho de 2010).

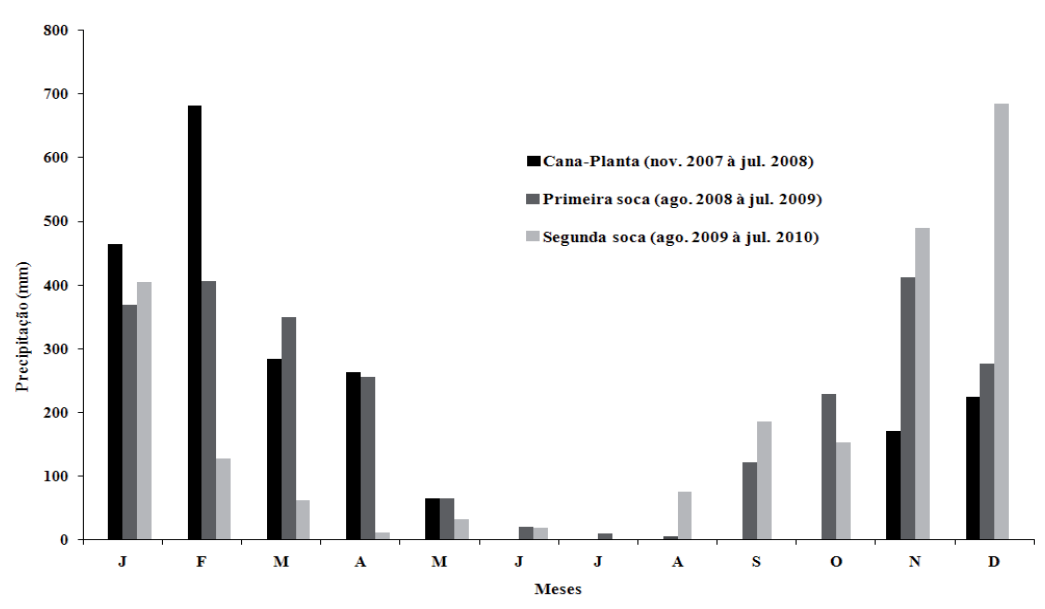

Fonte: Elaboração dos autores. 
O solo predominante da área experimental é o Latossolo Vermelho-Amarelo distrófico (SANTOS et al., 2006), o qual foi explorado com pastagem durante 15 anos. A análise granulométrica e química do solo foi realizada antes da instalação do experimento e os resultados observados na camada de 0,0 - 0,2 $\mathrm{m}$ de profundidade foram: $\operatorname{argila}=393 \mathrm{~g}$ $\mathrm{kg}^{-1}$; silte $=69 \mathrm{~g} \mathrm{~kg}^{-1}$ e areia $=538 \mathrm{~g} \mathrm{~kg}^{-1} ; \mathrm{pH}\left(\mathrm{CaCl}_{2}\right)=$ 4,4; M.O. $=14 \mathrm{~g} \mathrm{dm}^{-3} ; \mathrm{P}_{\text {-Mehlich } 1}=0,2 \mathrm{mg} \mathrm{dm}^{-3} ; \mathrm{K}^{+}=$ $1,0 \mathrm{mmol}_{\mathrm{c}} \mathrm{dm}^{-3} ; \mathrm{Ca}^{+2}=6,3 \mathrm{mmol}_{\mathrm{c}} \mathrm{dm}^{-3} ; \mathrm{Mg}^{+2}=1,3$ $\mathrm{mmol}_{\mathrm{c}} \mathrm{dm}^{-3},(\mathrm{H}+\mathrm{Al})=33,3 \mathrm{mmol}_{\mathrm{c}} \mathrm{dm}^{-3}, \mathrm{CTC}=44$ $\mathrm{mmol}_{\mathrm{c}} \mathrm{dm}^{-3}$ e $\mathrm{V} \%=23,8$. Na camada de $0,2-0,4$ $\mathrm{m}$ de profundidade os valores da análise química foram: $\mathrm{pH}\left(\mathrm{CaCl}_{2}\right)=4,3$; M.O. $=8 \mathrm{~g} \mathrm{dm}^{-3} ; \mathrm{P}_{\text {-Mehlich } 1}=$ $0,2 \mathrm{mg} \mathrm{dm}{ }^{-3} ; \mathrm{K}^{+}=0,4 \mathrm{mmol}_{\mathrm{c}} \mathrm{dm}^{-3} ; \mathrm{Ca}^{+2}=3,1 \mathrm{mmol}_{\mathrm{c}}$ $\mathrm{dm}^{-3} ; \mathrm{Mg}^{+2}=1,9 \mathrm{mmol}_{\mathrm{c}} \mathrm{dm}^{-3},(\mathrm{H}+\mathrm{Al})=28,3 \mathrm{mmol}_{\mathrm{c}}$ $\mathrm{dm}^{-3}, \mathrm{CTC}=34 \mathrm{mmol}_{\mathrm{c}} \mathrm{dm}^{-3}$ e V\%=16.

$\mathrm{O}$ delineamento experimental foi o de blocos ao acaso em arranjo fatorial 4 x 2, constituído por três fontes de $\mathrm{P}$ e um tratamento controle (sem $\mathrm{P}$ no sulco de plantio) e, duas variedades de canade-açúcar em quatro repetições, totalizando 32 unidades experimentais de 5,0 $\mathrm{m}$ x 7,0 m, sendo estas constituídas por seis linhas de cana espaçadas de 1,2 m. Considerou-se como área útil de cada parcela as quatro linhas centrais, deixando um metro de bordadura em cada extremidade.

As fontes de $\mathrm{P}$ utilizadas foram: superfosfato triplo ( $46 \%$ de $\mathrm{P}_{2} \mathrm{O}_{5}$ total e, 42,5\% solúvel em ácido cítrico a 2\%); fosfato natural reativo de Arad (33\% de $\mathrm{P}_{2} \mathrm{O}_{5}$ total e, $10,4 \%$ solúvel em ácido cítrico a $2 \%$ ); farinha de ossos $\left(12 \%\right.$ de $\mathrm{P}_{2} \mathrm{O}_{5}$ total e, $9,6 \%$ solúvel em ácido cítrico a $2 \%$ ), todas na dose de $100 \mathrm{~kg} \mathrm{ha}^{-1}$ de $\mathrm{P}_{2} \mathrm{O}_{5}$ total e; o controle. Utilizou-se a farinha de ossos desengordurada, sendo esta, passada por um processo de ebulição, tratamento com vapor d'água para a retirada da gordura. As variedades de canade-açúcar plantadas foram a IAC86-2480, de ciclo precoce, conhecida como cana forrageira e a SP791011, de ciclo intermediário, utilizada na indústria sucroalcooleira, porém, com alguns trabalhos que mostraram bom potencial desta variedade para fins de alimentação animal.
Para a correção da acidez do solo foi aplicado $2,35 \mathrm{Mg} \mathrm{ha}^{-1}$ de calcário (PRNT=100\%; $\mathrm{CaO}=30 \%$ e $\mathrm{MgO}=20 \%$ ) a lanço em área total e incorporado nas duas camadas de solo avaliadas, objetivando elevar a saturação por bases (V\%) para 50. A correção da acidez do solo e recomendação da adubação seguiram as indicações de Sousa e Lobato (2004).

Visto que o nível de $\mathrm{P}$ no solo encontravase muito baixo, efetuou-se a adubação fosfatada corretiva gradual (SOUSA; LOBATO, 2004), ou seja, de modo parcelado, aplicando $100 \mathrm{~kg} \mathrm{ha}^{-1} \mathrm{de}$ $\mathrm{P}_{2} \mathrm{O}_{5}$ total, utilizando o fosfato natural reativo de Arad, sendo distribuído igualmente em toda a área experimental e posteriormente incorporado.

O sistema de plantio adotado foi o de cana de ano, plantada no dia 14 do mês de novembro de 2007 . Para isto, foram abertos sulcos a uma profundidade de aproximadamente $0,20 \mathrm{~m}$. Em seguida, realizouse a adubação no sulco de plantio com as respectivas fontes de $\mathrm{P}$ e a adubação potássica, [cloreto de potássio $(\mathrm{KCl})]$, sendo distribuído igualmente em todas as parcelas, na dose de $80 \mathrm{~kg} \mathrm{ha}^{-1}$ de $\mathrm{K}_{2} \mathrm{O}$.

A adubação em cobertura da cana planta foi realizada aos 60 dias após o plantio, quando as plantas apresentaram aproximadamente $0,8 \mathrm{~m}$ de altura. Aplicaram-se $30 \mathrm{~kg}$ de ha-1 de $\mathrm{N}$ (uréia) e $40 \mathrm{~kg} \mathrm{ha}^{-1}$ de $\mathrm{K}_{2} \mathrm{O}$ via cloreto de potássio $(\mathrm{KCl})$ igualmente em todas as parcelas.

Para o controle de plantas daninhas foi aplicado herbicida à base de Dimethylammonium (2,4dichlorophenoxy) acetate, na dose de 1,5 $\mathrm{L} \mathrm{ha}^{-1}$, em jato dirigido e capina para plantas não controladas, igualmente em todos os ciclos da cultura.

A adubação em cobertura da cana soca (segundo e terceiro ciclos) foi realizada de forma manual quando as plantas se encontravam com aproximadamente $0,6 \mathrm{~m}$ de altura, aplicando-se 120 $\mathrm{kg} \mathrm{ha}^{-1}$ de $\mathrm{K}_{2} \mathrm{O}(\mathrm{KCl})$ e $60 \mathrm{~kg} \mathrm{ha}^{-1}$ de $\mathrm{N}$ (sulfato de amônio).

As avaliações e a colheita da cana-de-açúcar 
foram realizadas aos 240 dias após o plantio para a cana planta (julho de 2008), aos 390 dias para a primeira soca (agosto de 2009) e aos 360 dias para a segunda soca (agosto de 2010). Para a determinação da produtividade de matéria seca (MS), contaram-se os colmos existentes em duas linhas centrais de cada parcela. Em seguida, cortou-se 10 colmos + folhas em três linhas da área útil, totalizando 30 colmos + folhas por parcela para proceder a pesagem e a obtenção da produtividade de fitomassa. Em seguida, trituraram-se os colmos + folhas de cada parcela e, deste material foi retirada uma amostra de aproximadamente $500 \mathrm{~g}$, pesada e colocada em estufa de ventilação forçada a $60^{\circ} \mathrm{C}$ até obter a massa constante. Posteriormente, foi pesada novamente e verificado o teor de MS ( $\left.1^{\text {a }} \mathrm{MS}\right)$ e, assim, calculouse a produtividade de MS.

As determinações do valor nutritivo da forragem foram efetuadas no Laboratório de Bromatologia do Departamento de Zootecnia da UNESP - Ilha Solteira. Após cada corte da cana-de-açúcar para quantificação da primeira MS e produtividade de MS, a amostra (porção de aproximadamente $500 \mathrm{~g}$ de massa verde que foi utilizada para quantificação da $1^{\mathrm{a}} \mathrm{MS}$ ) de cada tratamento foi moída em moinho tipo "Willey" com peneira de malha de 1,0 mm para efetuar as análises. As determinações da digestibilidade in vitro da matéria seca (DIVMS), teor de matéria seca (MS), proteína bruta (PB) e dos componentes fibrosos, fibra insolúvel em detergente neutro (FDN), fibra insolúvel em detergente ácido (FDA), lignina (LIG) e celulose (CEL), as quais foram realizadas segundo metodologias descritas por Silva e Queiroz (2002), com algumas adaptações.
Para determinações das fibras, amostras $(0,50 \mathrm{~g})$ foram acondicionadas em sacos de TNT (tecido não tecido) de gramatura $100 \mathrm{~g} \mathrm{~cm}^{2}$ com dimensões de 5 x 5 cm (CASALI et al., 2009) e, mergulhados em Becker contendo $50 \mathrm{ml}$ de solução detergente neutro por amostra e submetidos à digestão em autoclaves à $105^{\circ} \mathrm{C}$ por 60 minutos (PELL; SCHOFIELD, 1993).

Os dados obtidos foram submetidos à análise de variância pelo teste $\mathrm{F}$ e comparação de médias pelo teste de Tukey a 5\% de probabilidade, utilizando o programa estatístico SISVAR ${ }^{\circledR}$ (FERREIRA, 2003).

\section{Resultados e Discussão}

\section{Cana planta $\left(1^{\circ}\right.$ ciclo)}

As fontes de $\mathrm{P}$ aplicadas no sulco de plantio causaram efeito significativo $(\mathrm{P}<0,01)$ para a produtividade de MS da cana planta, diferindo do controle. A aplicação de farinha de ossos superou em $46 \%$ o controle; o superfosfato triplo resultou em ganho percentual de $39 \%$ e; o fosfato de Arad em 29\% (Tabela 1). De acordo com Korndörfer e Melo (2009), avaliando fontes de P na dose de 100 $\mathrm{kg} \mathrm{ha}^{-1}$ de $\mathrm{P}_{2} \mathrm{O}_{5}$ em cana-de-açúcar cultivada em solo Podzólico Vermelho-Amarelo de textura média, distrófico no município de Pirassununga-SP, não houve diferença significativa para produtividade de MS, atingindo valores médios de $40 \mathrm{Mg} \mathrm{ha}^{-1}$ com o uso do superfosfato triplo. Observa-se que tanto no presente trabalho como no trabalho de Korndörfer e Melo (2009), apesar da igualdade estatística, as fontes de maior solubilidade proporcionaram produtividade superior, numericamente, ao fosfato de rocha. 
Tabela 1. Produtividade de matéria seca (Prod.), teor de matéria seca (MS), fibra insolúvel em detergente neutro (FDN) e em detergente ácido (FDA), lignina (LIG), celulose (CEL), digestibilidade in vitro da matéria seca (DIVMS) e proteína bruta $(\mathrm{PB})$ de variedades de cana-de-açúcar (cana planta), em função da aplicação de fontes de fósforo (100 $\mathrm{kg} \mathrm{ha}^{-1}$ de $\mathrm{P}_{2} \mathrm{O}_{5}$ ) no sulco de plantio. Alta Floresta - MT, 2008.

\begin{tabular}{|c|c|c|c|c|c|c|c|c|}
\hline \multirow{2}{*}{ Fontes de P } & Prod. & MS & FDN & FDA & LIG & CEL & DIVMS & PB \\
\hline & $\mathrm{Mg} \mathrm{ha}^{-1}$ & & & & $\%$ & & & \\
\hline Controle & $26,9 \mathrm{~b}$ & 23,0 & 53,2 & 32,3 & 2,0 & 26,7 & 65,1 & 3,1 \\
\hline Farinha de Ossos & 39,3 a & 23,0 & 56,2 & 33,6 & 1,9 & 28,1 & 62,5 & 3,3 \\
\hline Fosfato de Arad & $34,6 \mathrm{ab}$ & 23,7 & 55,0 & 33,6 & 1,8 & 27,8 & 62,8 & 3,2 \\
\hline Superfosfato Triplo & $37,5 \mathrm{a}$ & 25,3 & 54,1 & 32,5 & 2,0 & 27,1 & 65,7 & 3,3 \\
\hline \multicolumn{9}{|l|}{ Variedades } \\
\hline IAC86-2480 & 40,9 a & 23,4 & $58,6 \mathrm{a}$ & $35,7 \mathrm{a}$ & $2,0 \mathrm{a}$ & $29,4^{\mathrm{a}}$ & $59,8 \mathrm{~b}$ & $3,7 \mathrm{a}$ \\
\hline \multirow[t]{2}{*}{ SP79-1011 } & $28,2 \mathrm{~b}$ & 24,1 & $50,6 \mathrm{~b}$ & $30,3 b$ & $1,8 \mathrm{~b}$ & $25,5 b$ & $68,2 \mathrm{a}$ & $2,8 \mathrm{~b}$ \\
\hline & \multicolumn{8}{|c|}{ Valor de $\mathrm{F}$} \\
\hline Fonte $(\mathrm{P})$ & $7,0 * *$ & $1,5^{\text {ns }}$ & $0,5^{\mathrm{ns}}$ & $0,6^{\mathrm{ns}}$ & $1,7^{\mathrm{ns}}$ & $0,7^{\mathrm{ns}}$ & $1,7^{\mathrm{ns}}$ & $0,3^{\mathrm{ns}}$ \\
\hline Variedade (V) & $37,6 * *$ & $0,6^{\mathrm{ns}}$ & $17,8 * *$ & $32,3 * *$ & $9,8 * *$ & $22,7 * *$ & $47,3 * *$ & $33,0 * *$ \\
\hline $\mathrm{P} \times \mathrm{V}$ & $0,2^{\text {ns }}$ & $2,1^{\mathrm{ns}}$ & $0,7^{\mathrm{ns}}$ & $0,7^{\mathrm{ns}}$ & $1,2^{\mathrm{ns}}$ & $0,7^{\mathrm{ns}}$ & $0,6^{\mathrm{ns}}$ & $1,3^{\text {ns }}$ \\
\hline $\mathrm{CV}(\%)$ & 17,0 & 10,7 & 9,9 & 8,1 & 11,5 & 8,5 & 5,4 & 12,7 \\
\hline
\end{tabular}

Médias seguidas de letras distintas, nas colunas, diferem estatisticamente entre si, ao nível de 5\% de probabilidade, pelo teste de Tukey. ${ }^{\text {ns }}$ Não significativo. ** e* Significativo a 1 e $5 \%$ de probabilidade, respectivamente.

Fonte: Elaboração dos autores.

Entre as variedades de cana-de-açúcar, observa-se que a IAC86-2480 apresentou maior produtividade, sendo esta, $31 \%$ superior a produtividade obtida com a SP79-1011. Resultados obtidos com a variedade IAC86-2480 por Leite et al. (2010), avaliando o desenvolvimento e produtividade de variedades de cana-de-açúcar no estado do Tocantins, foi de 63,0 $\mathrm{Mg} \mathrm{ha}^{-1}$, superior ao valor encontrado no presente estudo e, ao obtido por Freitas et al. (2006) que foi de 20,1 $\mathrm{Mg} \mathrm{ha}^{-1}$ de MS. Leite et al. (2010), observaram produtividade de 41,3 $\mathrm{Mg} \mathrm{ha}^{-1}$, com a variedade SP79-1011.

Analisando o valor nutricional da cana planta, colhida aos 240 DAP, nota-se que não houve efeito significativo das fontes de $\mathrm{P}$ nos teores de MS, FDN, FDA, LIG, CEL, DIVMS e PB da MS. Ao se analisar os resultados obtidos com as variedades, observa-se que houve diferença significativa, atribuindo melhores resultados para a SP79-1011. Santana et al. (2010), avaliando o efeito da aplicação de doses de corretivos de acidez sobre a composição bromatológica do capim Mombaça, verificaram que não houve alterações para estas variáveis. Fabricio et al. (2010), avaliando o efeito de doses de NPK na composição bromatológica do capim Tobiatã, verificaram que o $\mathrm{N}$ promoveu elevação nos teores de $\mathrm{PB}$, com diminuição nos teores de FDN e FDA e, o $\mathrm{P}$ e o $\mathrm{K}$ não causaram alterações. Cecato et al. (2004) também não observaram influência da adubação fosfatada sobre os parâmetros qualitativos (PB, FDN, FDA e DIVMS) do capim Marandu, corroborando com os resultados obtidos no presente trabalho com a cana-de-açúcar.

$O$ teor de MS não foi influenciado significativamente pelas fontes de $\mathrm{P}$ e nem pelas variedades $(\mathrm{P}>0,05)$, demonstrando valores abaixo do encontrado na maioria dos trabalhos com cana-de-açúcar em estádio final de maturação. De acordo com Fernandes et al. (2003), as variedades de ciclo precoce e intermediário não apresentaram diferenças significativas em relação ao teor de MS, encontrando valores médios de $29 \%$.

A variedade SP79-1011 apresentou valores mais baixos de FDN, FDA, LIG e CEL conferindolhe desta maneira boa aptidão para o uso na alimentação animal, pois estas frações são de 
maiores dificuldades de degradação no sistema digestivo animal. Dessa forma, a maior DIVMS encontrada para a variedade SP79-1011, está relacionada, principalmente, ao menor teor de LIG e CEL que a IAC86-2480, havendo, portanto, correlação negativa entre estas frações fibrosas com a digestibilidade e aproveitamento de nutrientes pelos animais, conforme ressaltado por Silva e Queiroz (2002). Ainda de acordo com os autores, a FDA é a porção menos digerível da parede celular das forrageiras pelos microrganismos do rúmen, sendo constituída na sua quase totalidade de lignina e celulose.

Segundo Van Soest (1994), quanto maior o teor de FDA menor será a digestibilidade, enquanto que a FDN tem correlação negativa com o consumo das forrageiras, considerando teores de $40 \%$ de FDA e $60 \%$ de FDN, como limitantes da digestibilidade e do consumo, respectivamente. Sendo assim, os valores encontrados para estas frações no presente estudo estão dentro da faixa não limitante para a digestibilidade e o consumo.

A variedade IAC86-2480 apresentou maior teor de $\mathrm{PB}$, demonstrando, também, boa aptidão para fins forrageiros, visto que esta é uma das principais características que limita o uso da cultura na alimentação animal. Andrade et al. (2004) verificaram menores valores médios $(2,59 \%)$ de PB para 60 variedades, colhidas aos 12 e 18 meses, valendo ressaltar que algumas dessas variedades testadas pelos autores apresentaram teores muito baixo de PB (1,91\% de PB) o que contribui para este menor valor médio, já que algumas variedades apresentaram valores mais elevados (3,20\% de PB), sendo semelhante ao presente estudo.

\section{Cana soca $\left(2^{\circ}\right.$ ciclo $)$}

Avaliando o efeito residual do $\mathrm{P}$, aplicado na ocasião do plantio da cana-de-açúcar, sobre a produtividade de MS da primeira soca, verifica-se que não houve efeito significativo (Tabela 2). Em relação as variedades, observa-se considerável redução da produtividade do primeiro para o segundo corte, sendo que a IAC86-2480 apresentou queda de $21 \%$, enquanto que a SP79-1011 apresentou queda de $30,5 \%$. A maior queda de produtividade observada para a SP79-1011 pode estar relacionada ao baixo índice pluviométrico no início de brotação do segundo ciclo (agosto e setembro de 2008, Figura 1), demonstrando ser uma variedade mais sensível ao estresse hídrico. Tomaz (2009), avaliando o efeito residual de fontes de $\mathrm{P}$, verificou que houve redução de $40 \%$ na produtividade da cana planta para a cana soca e, também não verificou efeito significativo das fontes de $\mathrm{P}$ sobre a produtividade.

Observa-se que o teor de MS não foi influenciado pelas fontes de $\mathrm{P}$ e, entre as variedades, o valor médio encontrado na SP79-1011 foi superior ao encontrado na IAC86-2480, diferenciando significativamente $(\mathrm{P}<0,01)$. Estes teores de MS estão em concordância com a maioria dos trabalhos apresentados na literatura (CARVALHO, 1992; PEREIRA et al., 2001; FERNANDES et al., 2003), demonstrando que neste ciclo, ambas variedades se encontravam em estádio final de maturidade.

Houve efeito significativo $(\mathrm{P}<0,05)$ para as fontes de P em relação a FDN e FDA, verificandose maiores valores quando se utilizou $\mathrm{P}$ na forma de superfosfato triplo, não diferenciando do fosfato de Arad e da ausência da aplicação de P no sulco de plantio. Utilizando P na forma de farinha de ossos, observaram-se menores teores de FDN e FDA. Atribui-se este efeito, possivelmente, à composição química dos fertilizantes, sendo que, além do conhecido teor de P em cada fonte, também, há outros elementos que podem influenciar na composição da forragem. Entre as variedades não se verificou diferenças $(\mathrm{P}>0,05)$. Estes resultados assemelhamse com a média obtida por Andrade et al. (2004), avaliando 60 variedades de cana-de-açúcar. 
Tabela 2. Produtividade de matéria seca (Prod.), teor de matéria seca (MS), fibra insolúvel em detergente neutro (FDN) e em detergente ácido (FDA), lignina (LIG), celulose (CEL) e proteína bruta (PB) de variedades de cana-deaçúcar ( $2^{\circ}$ ciclo), em função do efeito residual de fontes de fósforo $\left(100 \mathrm{~kg} \mathrm{ha}^{-1} \mathrm{de}_{2} \mathrm{O}_{5}\right)$, aplicadas no sulco de plantio. Alta Floresta - MT, 2009.

\begin{tabular}{|c|c|c|c|c|c|c|c|}
\hline \multirow{2}{*}{ Fontes de P } & Prod. & MS & FDN & FDA & LIG & CEL & PB \\
\hline & $\mathrm{Mg} \mathrm{ha}^{-1}$ & \multicolumn{6}{|c|}{$\%$} \\
\hline Controle & 21,1 & 25,8 & $53,7 \mathrm{ab}$ & $32,1 \mathrm{ab}$ & 3,5 & 26,8 & 3,5 \\
\hline Farinha de Ossos & 29,1 & 27,8 & $52,6 \mathrm{~b}$ & $31,8 b$ & 3,3 & 26,5 & 3,4 \\
\hline Fosfato de Arad & 26,7 & 26,6 & $55,2 \mathrm{ab}$ & $32,9 \mathrm{ab}$ & 3,3 & 27,4 & 3,4 \\
\hline Superfosfato Triplo & 26,6 & 26,0 & $60,0 \mathrm{a}$ & $36,8 \mathrm{a}$ & 3,8 & 29,0 & 3,4 \\
\hline \multicolumn{8}{|l|}{ Variedades } \\
\hline IAC86-2480 & $32,3 \mathrm{a}$ & $25,4 b$ & 55,5 & 33,5 & 3,6 & 27,7 & $3,8 \mathrm{a}$ \\
\hline SP79-1011 & $19,6 \mathrm{~b}$ & $27,7 \mathrm{a}$ & 55,3 & 33,3 & 3,4 & 27,2 & $3,1 \mathrm{~b}$ \\
\hline \multicolumn{8}{|c|}{ Valor de F } \\
\hline Fonte $(\mathrm{P})$ & $1,7^{\mathrm{ns}}$ & $2,7^{\mathrm{ns}}$ & $4,0^{*}$ & $3,4^{*}$ & $1,2^{\mathrm{ns}}$ & $3,0^{\mathrm{ns}}$ & $0,2^{\text {ns }}$ \\
\hline Variedade (V) & $27,4 * *$ & $18,7 * *$ & $0,1^{\text {ns }}$ & $0,1^{\text {ns }}$ & $0,4^{\mathrm{ns}}$ & $0,8^{\mathrm{ns}}$ & $16,3 * *$ \\
\hline $\mathrm{P} \times \mathrm{V}$ & $0,3^{\mathrm{ns}}$ & $0,1^{\mathrm{ns}}$ & $0,4^{\mathrm{ns}}$ & $0,8^{\mathrm{ns}}$ & $6,0 * *$ & $0,5^{\mathrm{ns}}$ & $0,5^{\mathrm{ns}}$ \\
\hline CV (\%) & 26,4 & 5,8 & 8,3 & 10,6 & 17,3 & 6,6 & 14,7 \\
\hline
\end{tabular}

Médias seguidas de letras distintas, nas colunas, diferem estatisticamente entre si, ao nível de 5\% de probabilidade, pelo teste de Tukey. ${ }^{\text {ns }}$ Não significativo. ** e* Significativo a 1 e $5 \%$ de probabilidade, respectivamente.

Fonte: Elaboração dos autores.

Os fatores fontes de $\mathrm{P}$ e variedades de cana-deaçúcar apresentaram interação significativa para LIG $(\mathrm{P}<0,01)$ e; analisando o desdobramento da interação (Tabela 3), observa-se que ao se utilizar a farinha de ossos a variedade IAC86-2480 apresentou maior teor de LIG que a SP79-1011. Porém, o efeito de fontes dentro de variedades só foi observado para a SP79-1011, verificando que o superfosfato triplo foi a fonte que proporcionou maior teor de LIG, sem diferenciar do fosfato de Arad e do controle.

Tabela 3. Desdobramento da interação entre fontes de fósforo e variedades de cana-de-açúcar $\left(2^{\circ}\right.$ ciclo), para teor de lignina em função do efeito residual de fontes de fósforo $\left(100 \mathrm{~kg} \mathrm{ha}^{-1}\right.$ de $\left.\mathrm{P}_{2} \mathrm{O}_{5}\right)$ aplicadas no sulco de plantio. Alta Floresta - MT, 2009.

\begin{tabular}{lccc}
\hline & & Variedades & \\
Fontes de P & IAC86-2480 & SP79-1011 \\
\cline { 2 - 3 } & & Lignina (\%) & $3,36 \mathrm{abA}$ \\
Controle & $3,60 \mathrm{aA}$ & $2,56 \mathrm{bB}$ \\
Farinha de Ossos & $4,15 \mathrm{aA}$ & $3,71 \mathrm{abA}$ \\
Fosfato de Arad & $2,99 \mathrm{aA}$ & $4,13 \mathrm{aA}$ \\
Superfosfato Triplo & $3,56 \mathrm{aA}$ & \\
\hline
\end{tabular}

Médias seguidas por mesmas letras, minúsculas nas colunas e, maiúsculas nas linhas, não diferem estatisticamente entre si, ao nível de $5 \%$ de probabilidade, pelo teste de Tukey.

Fonte: Elaboração dos autores. 
Andrade et al. (2004), avaliando a composição bromatológica de 60 variedades de cana-de-açúcar em função da idade de corte, verificaram valores de $2,8 \%$ a 3,3\% de LIG para a variedade SP79-1011 aos 12 e 18 meses, respectivamente, demonstrando assim, maior valor para esta fração com o avanço da idade da planta.

Para a CEL e $\mathrm{PB}$, as fontes de $\mathrm{P}$ não exerceram efeito significativo $(\mathrm{P}>0,05)$ (Tabela 2). Para a $\mathrm{PB}$, a variedade IAC86-2480 foi superior $(\mathrm{P}<0,01)$, mantendo os mesmos níveis de PB do primeiro ciclo. Fernandes et al. (2003), encontraram valores que variaram de $2,61 \%$ a $2,90 \%$ de $\mathrm{PB}$.

\section{Cana soca $\left(3^{\circ}\right.$ ciclo $)$}

Avaliando o efeito residual do $\mathrm{P}$, aplicado no sulco de plantio, sobre a produtividade de MS das variedades de cana-de-açúcar no terceiro ciclo, verifica-se que não houve significância $(\mathrm{P}>0,05)$ para os tratamentos que receberam a aplicação de $\mathrm{P}$, em relação ao controle (Tabela 4). A dose aplicada (100 kg ha-1 de $\mathrm{P}_{2} \mathrm{O}_{5}$ total) pode não ter sido suficiente para causar efeito significativo na produtividade durante o terceiro ciclo, uma vez que, na cana soca não foi efetuada a adubação fosfatada. Outro possível fator que favoreceu para a não manifestação de efeitos significativos é o tipo de solo da área experimental, já que favorece os processos de adsorção e precipitação de $\mathrm{P}$.

Tabela 4. Produtividade de matéria seca (Prod.), teor de matéria seca (MS), fibra insolúvel em detergente neutro (FDN) e em detergente ácido (FDA), lignina (LIG), celulose (CEL), digestibilidade in vitro da matéria seca (DIVMS) e proteína bruta $(\mathrm{PB})$ de variedades de cana-de-açúcar $\left(3^{\circ}\right.$ ciclo), em função da aplicação de fontes de fósforo $(100 \mathrm{~kg}$ ha ${ }^{-1}$ de $\mathrm{P}_{2} \mathrm{O}_{5}$ ) no sulco de plantio. Alta Floresta - MT, 2010.

\begin{tabular}{|c|c|c|c|c|c|c|c|c|}
\hline \multirow{2}{*}{ Fontes de $\mathrm{P}$} & Prod. & MS & FDN & FDA & LIG & CEL & DIVMS & $\mathrm{PB}$ \\
\hline & $\mathrm{Mg} \mathrm{ha}^{-1}$ & \multicolumn{6}{|c|}{$\%$} & \\
\hline Controle & 28,0 & 28,2 & 41,1 & 27,1 & 2,7 & 22,1 & $68,8 \mathrm{a}$ & 2,4 \\
\hline Farinha de Ossos & 33,8 & 31,1 & 43,0 & 28,4 & 2,7 & 23,2 & $67,4 \mathrm{ab}$ & 2,3 \\
\hline Fosfato de Arad & 35,3 & 29,7 & 45,2 & 29,7 & 2,8 & 24,3 & $65,2 b$ & 2,7 \\
\hline Superfosfato Triplo & 33,2 & 31,0 & 44,2 & 28,8 & 2,7 & 23,5 & $66,0 \mathrm{ab}$ & 2,3 \\
\hline \multicolumn{9}{|l|}{ Variedades } \\
\hline IAC $86-2480$ & 32,4 & 29,2 & 42,5 & 28,0 & 2,8 & 22,8 & 67,0 & $2,9 a$ \\
\hline \multirow[t]{2}{*}{ SP79-1011 } & 32,8 & 30,9 & 44,3 & 29,0 & 2,6 & 23,8 & 66,7 & $2,0 \mathrm{~b}$ \\
\hline & & \multicolumn{6}{|c|}{ Valor de F } & \\
\hline Fonte $(\mathrm{P})$ & $2,48^{\mathrm{ns}}$ & $2,5^{\text {ns }}$ & $2,8^{\text {ns }}$ & $2,5^{\mathrm{ns}}$ & $0,3^{\text {ns }}$ & $2,7^{\mathrm{ns}}$ & $4,8^{*}$ & $2,3^{\mathrm{ns}}$ \\
\hline Variedade (V) & $0,04^{\mathrm{ns}}$ & $3,8^{\mathrm{ns}}$ & $2,8^{\text {ns }}$ & $2,3^{\text {ns }}$ & $3,1^{\mathrm{ns}}$ & $2,9^{\text {ns }}$ & $0,2^{\text {ns }}$ & $56,1 * *$ \\
\hline $\mathrm{P} \times \mathrm{V}$ & $0,67^{\mathrm{ns}}$ & $0,8^{\mathrm{ns}}$ & $0,9^{\mathrm{ns}}$ & $0,8^{\mathrm{ns}}$ & $1,5^{\mathrm{ns}}$ & $0,5^{\mathrm{ns}}$ & $1,2^{\mathrm{ns}}$ & $0,3^{\text {ns }}$ \\
\hline $\mathrm{CV}(\%)$ & 17,6 & 8,1 & 7,0 & 6,8 & 10,0 & 6,9 & 3,0 & 13,4 \\
\hline
\end{tabular}

Médias seguidas de letras distintas, nas colunas, diferem estatisticamente entre si, ao nível de 5\% de probabilidade, pelo teste de Tukey. ${ }^{\text {ns }}$ Não significativo. $* *$ e $*$ Significativo a 1 e $5 \%$ de probabilidade, respectivamente.

Fonte: Elaboração dos autores.

Comparando a produtividade das variedades também não houve diferença significativa. Observa-se que a variedade IAC86-2480 manteve a mesma média de produtividade, em relação ao ciclo anterior. Já a variedade SP79-1011 apresentou um comportamento inesperado, que foi de acréscimo de produtividade de MS de 67\%, em relação ao segundo ciclo. Sendo assim, verifica-se que a variedade SP79-1011 foi mais afetada pelo baixo índice pluviométrico no início de brotação do segundo ciclo, pois, no terceiro ciclo, em que houve maior precipitação pluvial no início de brotação 
(Figura 1), ocorreu acréscimo de produtividade em relação ao segundo ciclo.

Resultados semelhantes foram obtidos por Tomaz (2009), que não verificou efeito significativo dos fatores doses, formas de aplicação e fontes de P, no terceiro ciclo da cultura.

Avaliando o valor nutricional da cana-de-açúcar, observa-se que houve efeito significativo das fontes de $\mathrm{P}$ apenas para DIVMS $(\mathrm{P}<0,05)$. Já as variedades diferiram significativamente $(\mathrm{P}<0,01)$ em relação a PB, sendo que a variedade IAC86-2480 apresentou resultados superiores. Os valores obtidos estão de acordo com os resultados encontrados no trabalho de Oliveira et al. (1999).

Para o teor de MS, FDN, FDA, LIG e CEL não houve significância para os fatores avaliados $(\mathrm{P}>0,05)$. De forma geral, pode-se inferir que as maiores variações para as frações fibrosas e, consequentemente para digestibilidade obtidas entre as variedades no primeiro ciclo, estão mais relacionadas com a idade das plantas do que com as variedades estudadas, já que, para cana soca colhida por volta de 390 e 360 dias, segundo e terceiro ciclo, respectivamente, não foi verificado diferença significativa entre as variedades. Mello et al. (2006), avaliando a composição bromatológica de nove variedades de cana-de-açúcar, verificaram valores médios de $24,8 \%$ de $\mathrm{MS}, 1,9 \%$ de $\mathrm{PB}$, $44,9 \%$ de FDN, $29,2 \%$ de FDA e $11,4 \%$ de LIG para a variedade SP79-1011.

A maior digestibilidade obtida com o tratamento controle, seguido do superfosfato triplo e da farinha de ossos, pode estar relacionada à composição química dos adubos utilizados, observandose que o fosfato de Arad proporcionou menor digestibilidade da MS. Pode-se relacionar este fato com a composição deste fertilizante que, possui de 0,5 a 6,0 \% de $\mathrm{SiO}_{2}$ (OURO VERDE, 2008) e, como a cana-de-açúcar é uma cultura acumuladora de silício ( $\mathrm{Si}$ ), este efeito pode ter contribuído para causar menor digestibilidade, já que o Si tem função estrutural na parede celular, podendo desta forma, elevar os conteúdos de LIG e CEL, aumentando a rigidez da parede celular.

De forma geral, as variedades de cana-de-açúcar apresentaram altas produtividades, destacando a variedade IAC86-2480, sobretudo no primeiro ciclo, em que foi observada a maior eficiência da adubação fosfatada, proporcionando incrementos significativos na produtividade da cultura. A ausência de resposta da cultura a adubação fosfatada, quando se avaliou o efeito residual das adubações nas diferentes fontes (segundo e terceiro ciclo), ocorreu provavelmente, devido a dose utilizada ter sido baixa, considerando três ciclos de produção e, como no primeiro ano após a aplicação do $\mathrm{P}$ a disponibilidade é normalmente maior, houve maior absorção e consequentemente exportação de $\mathrm{P}$ pelas plantas. E, devido à afinidade do íon fosfato pelos componentes da fração argila do solo, ocorre a formação de $\mathrm{P}$ mineralogicamente estável com o passar do tempo, diminuindo a disponibilidade para as plantas.

\section{Conclusões}

A aplicação de $100 \mathrm{~kg} \mathrm{ha}^{-1}$ de $\mathrm{P}_{2} \mathrm{O}_{5}$ promoveu maiores produtividades durante o primeiro ciclo da cana-de-açúcar e não causaram efeito significativo na produtividade nos ciclos posteriores.

A adubação fosfatada não promoveu alterações significativas no valor nutricional da cana-deaçúcar.

A variedade IAC86-2480 apresentou maior teor de proteína bruta nos três ciclos e maior produtividade de matéria seca nos dois primeiros ciclos.

As variedades de cana-de-açúcar apresentaram teores semelhantes de constituintes fibrosos.

\section{Referências}

ANDRADE, J. B.; FERRARI JÚNIOR, E.; POSSENTI, R. A.; OTSUK, I. P.; ZIMBACK, L.; LANDELL, M. G. A. Composição química de genótipos de cana-de-açúcar 
em duas idades, para fins de nutrição animal. Bragantia, Campinas, v. 63, n. 3, p. 341-349, 2004.

AVELAR, A. C.; FERREIRA, W. M.; BRITO, W.; MENEZES, M. A. B. C. Composição mineral de fosfatos, calcário e farinha de ossos usados na Agropecuária Brasileira. Archivos de Zootecnia, Córdoba, v. 58, n. 224, p. 737-740, 2009.

CARVAlHO, G. J. Avaliação do potencial forrageiro $e$ industrial de variedades de cana-de-açúcar (ciclo de ano) em diferentes épocas de corte. 1992. Dissertação (Mestrado em Fitotecnia) - Escola Superior de Agricultura de Lavras, Lavras.

CASALI, A. O.; DETMANN, E.; VALADARES FILHO, S. C.; PEREIRA, J. C.; CUNHA, M.; DETMANN, K. S. C.; PAULINO, M. F. Estimação de teores de componentes fibrosos em alimentos para ruminantes em sacos de diferentes tecidos. Revista Brasileira de Zootecnia, Viçosa, v. 38, n. 1, p. 130-138, 2009.

CECATO, U.; PEREIRA, L. A. F.; JOBIM, C. C.; MARTINS, E. N.; BRANCO, A. F.; GALBEIRO, S. MACHADO, A. O. Influência das adubações nitrogenada e fosfatada sobre a composição químico-bromatológica do capim Marandu (Brachiaria brizantha (Hochst) Stapf cv. Marandu). Acta Scientiarum. Animal Sciences, Maringá, v. 26, n. 3, p. 409-416, 2004.

FABRICIO, J. A.; BUZETTI, S.; BERGAMASCHINE, A. F.; BENETT, C. G. S. Produtividade e composição bromatológica do capim-Tobiatã com adubação NPK. Acta Scientiarum. Agronomy, Maringá, v. 32, n. 2, p. 333-337, 2010.

FERNANDES, A. M.; QUEIROZ, A. C.; LANA, R. P.; PEREIRA, J. C.; CABRAL, L. S.; VITTORI, A.; PEREIRA, E. S. Estimativas da produção de leite por vacas holandesas mestiças, segundo o sistema CNCPS, em dietas contendo cana-de-açúcar com diferentes valores nutritivos. Revista Brasileira de Zootecnia, Viçosa, v. 30, n. 4, p. 1350-1357, 2001.

FERNANDES, A. M.; QUEIROZ, A. C.; PEREIRA, J. C.; LANA, R. P.; BARBOSA, M. H. P.; FONSECA, D. M.; DETMANN, E.; CABRAL, L. S.; PEREIRA, E. S.; VITTORI, A. Composição químico-bromatológica de variedades de cana-de-açúcar (Saccharum spp L.) com diferentes ciclos de produção (precoce e intermediário) em três idades de corte. Revista Brasileira de Zootecnia, Viçosa, v. 32, n. 4, p. 977-985, 2003.

FERREIRA, D. F. Sisvar: sistema de análise de variância. Versão 4.6. Lavras: UFLA/DEX, 2003.

FREITAS, A. W. P.; PEREIRA, J. C.; ROCHA, F. C.; DETMANN, E.; BARBOSA, M. H. P.; RIBEIRO, M. D.; COSTA, M. G. Avaliação da divergência nutricional de genótipos de cana-de-açúcar (Saccharum spp.). Revista Brasileira de Zootecnia, Viçosa, v. 35, n. 1, p. 229-236, 2006.

HOROWITZ, N.; MEURER, E. J. Eficiência de dois fosfatos naturais farelados em função do tamanho da partícula. Ciência Rural, Santa Maria, v. 33, n. 1, p. 4147, 2003.

KORNDÖRFER, G. H.; MELO, S. P. Fontes de fósforo (fluida ou sólida) na produtividade agrícola e industrial da cana-de-açúcar. Revista Ciência e Agrotecnologia, Lavras, v. 33, n. 1, p. 92-97, 2009.

LEITE, R. L. L.; SANTOS, A. C.; OLIVEIRA, L. B. T.; ARAÚJO, A. S.; NEIVA, J. N. M. Produção e desenvolvimento de cultivares de cana-de-açúcar em Argissolo Vermelho eutroférrico no Estado do Tocantins, Brasil. Revista Amazônia: Ciência e Desenvolvimento, Belém, v. 5, n. 10, p. 181-194, 2010.

MELLO, S. Q. S.; FRANÇA, A. F. S.; LIMA, M. L. M.; RIBEIRO, D. S.; MIYAGI, E. S.; REIS, J. G. Parâmetros do valor nutritivo de nove variedades de cana-de-açúcar cultivadas sob irrigação. Ciência Animal Brasileira, Goiânia, v. 7, n. 4, p. 373-380, 2006.

NOVAIS, R. F.; SMYTH, T. J. Fósforo em solos e planta em condições tropicais. Viçosa: Universidade Federal de Viçosa, 1999. 399 p.

OLIVEIRA, M. D. S.; TOSI, H.; SAMPAIO, A. A. M.; VIEIRA, P. F.; SANTIAGO, G. Avaliação de duas variedades de cana-de-açúcar submetidas a diferentes tempos de armazenamento. Pesquisa Agropecuária Brasileira, Brasília, v. 34, n. 8, p. 1435-1442, 1999.

OURO VERDE. Ficha de informação de segurança de produto químico-FISPQ. Fosfato natural reativo. Bunge S/A. 2008. Disponível em: <http://www.fertiouroverde. com.br/produtos/fispq.aspx>. Acesso em: 15 dez. 2010.

PELL, A. N.; SCHOFIELD, P. Computerized monitoring of gas production to measure forage digestion in vitro. Journal of Dairy Science, Savoy, v. 76, n. 4, p. 10631073, 1993.

PEREIRA, E. S.; QUEIROZ, A. C.; PAULINO, M. F.; CECON, P. R.; VALADARES FILHO, S. C.; MIRANDA, L. F.; ARRUDA, A. M. V.; FERNANDES, A. M.; CABRAL, L. S. Fontes nitrogenadas e uso de Sacharomyces cereviseae em dietas à base de cana-deaçúcar para novilhos: consumo, digestibilidade, balanço nitrogenado e parâmetros ruminais. Revista Brasileira de Zootecnia, Viçosa, v. 30, n. 2, p. 563-572, 2001.

RESENDE, J. A.; PEREIRA, M. N.; PINHO, R. G. V.; FONSECA, A. H.; SILVA, A. R. P. Ruminal silage degradability and productivity of forage. Scientia Agrícola, Piracicaba, v. 60, n. 3, p. 457-463, 2003. 
SALAZAR, D. R.; STABILE, S. S.; GUIMARÃES, P. S.; PATERNIANI, M. E. A. G. Z.; SANTOS, M. G.; SILVA, L. F. P. Valor nutritivo do colmo de híbridos de milho colhidos em três estádios de maturidade. Pesquisa Agropecuária Brasileira, Brasília, v. 45, n. 7, p. 758-766, jul. 2010.

SANTANA, G. S.; BIANCHI, P. P. M.; MORITA, I. M.; ISEPON, O. J.; FERNANDES, F. M. Produção e composição bromatológica da forragem do capimmombaça (Panicum maximum Jacq.), submetidos a diferentes fontes e doses de corretivo de acidez. Semina: Ciências Agrárias, Londrina, v. 31, n. 1, p. 241-246, 2010.

SANTOS, H. G.; JACOMINE, P. K. T.; ANJOS, L. H. C.; OLIVEIRA, V. A.; OLIVEIRA, J. B.; COELHO, M. R.; LUMBRERAS, J. F.; CUNHA, T. J. F. (Ed.). Sistema brasileiro de classificação de solos. Rio de Janeiro: Embrapa Solos, 2006. 306 p.
SANTOS, H. Q.; FONSECA, D. M.; CANTARUTTI, R. B.; ALVAREZ, V. H.; NASCIMENTO JÚNIOR, D. Níveis críticos de fósforo no solo e na planta para gramíneas forrageiras tropicais, em diferentes idades. Revista Brasileira de Ciências do Solo, Viçosa, v. 26, n. 1, p. 173-182, 2002.

SILVA, D. J.; QUEIROZ, A. C. Análise de alimentos: métodos químicos e biológicos. 3. ed. Viçosa, MG: UFV, 2002. $235 \mathrm{p}$.

SOUSA, D. M. G.; LOBATO, E. Cerrado - correção do solo e adubação. 2. ed. Brasília: Embrapa Informação Tecnológica/Embrapa-CPA, 2004. 416 p.

TOMAZ, H. V. Q. Fontes, doses e formas de aplicação de fósforo na cana-de-açúcar. 2009. Dissertação (Mestrado em Fitotecnia) - Escola Superior de Agricultura Luiz de Queiroz, Piracicaba.

Van SOEST, P. J. Nutritional ecology of the ruminant. 2. ed. New York: Cornell University, 1994. 476 p. 